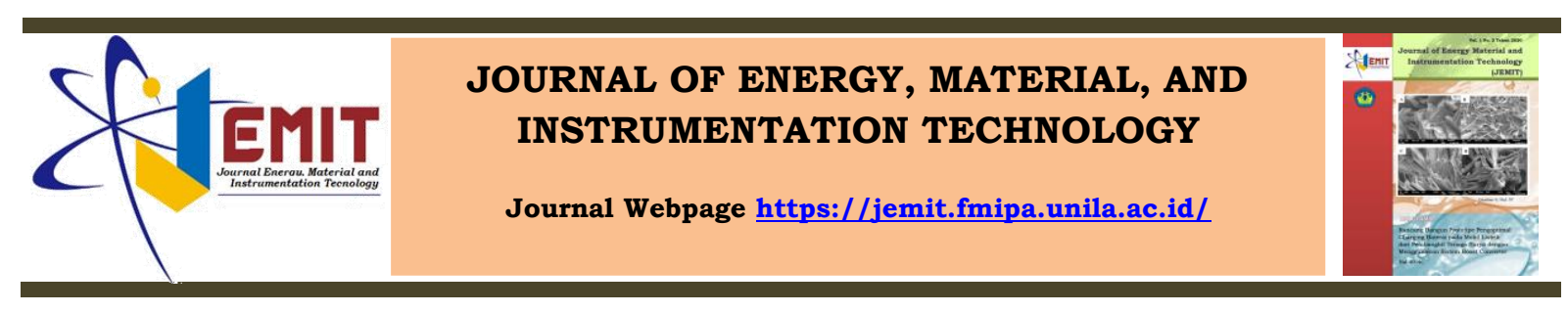

\title{
Pengaruh Variasi Suhu Sintering Menggunakan Metode Pencampuran Basah
}

\author{
M. Muntamijayati, Suprihatina, Yanti Yuliantib, dan Simon Sembiring \\ Jurusan Fisika, Universitas Lampung, Bandar Lampung, Indonesia, 35141
}

\begin{tabular}{|c|c|}
\hline Article Information & Abstract \\
\hline $\begin{array}{l}\text { Article history: } \\
\text { Received May } 5^{\text {th }}, 2020 \\
\text { Received in revised form } \\
\text { May } 15^{\text {th }}, 2020 \\
\text { Accepted July } 10^{\text {th }}, 2020 \\
\text { Keywords: } \\
\text { Superconductors, Sintering } \\
\text { temperature variation }\end{array}$ & $\begin{array}{l}\text { The superconducting material BPSCCO-2212 with doping Pb }=0,2 \text { has been } \\
\text { synthesized by the wet mixing method. Calculation is caried out at } 800{ }^{\circ} \mathrm{C} \text { for } 10 \\
\text { hours. While sintering is done at } 825{ }^{\circ} \mathrm{C}, 830{ }^{\circ} \mathrm{C}, 835{ }^{\circ} \mathrm{C} \text { and } 840{ }^{\circ} \mathrm{C} \text { for } 20 \text { hours. } \\
\text { The synthesis result were characterized by XRD X-Ray Diffraction) and SEM } \\
\text { (Scanning Electron Microscopy). The XRD spectrum analysis results that have been } \\
\text { processed using celref, show that in general the samples produced have formed the } \\
\text { BPSCCO-2212 phase (indicated the presence of Bi-2212 peaks) and have been } \\
\text { oriented (indicated the existence of peaks with } h=k=0 \text {, leven number). For the } \\
\text { calculation result obtanced the highest volume fraction value at } 830{ }^{\circ} \mathrm{C} \text { sintering } \\
\text { temperature with a value } \mathrm{FV}=66,97 \% \text { and the highest degree of orientation at } 825 \\
{ }^{\circ} \mathrm{C} \text { with a value of } P=76,54 \% \text {. The results of the SEM photo recorder generally show } \\
\text { that the crystals formed are oriented. }\end{array}$ \\
\hline
\end{tabular}

Informasi Artikel

Proses artikel:

Diterima 5 Mei 2020

Diterima dan direvisi dari

15 Mei 2020

Accepted 10 Juli 2020

\section{Kata kunci:}

Superkonduktor,

variasi suhu

sintering,

\begin{abstract}
Abstrak
Bahan superkonduktor BPSCCO-2212 dengan doping $\mathrm{Pb}=0,2$ telah disintesis dengan metode pencampuran basah. Kalsinasi dilakukan pada suhu $800{ }^{\circ} \mathrm{C}$ selama 10 jam. Sedangkan sintering dilakukan pada suhu $825^{\circ} \mathrm{C}, 830^{\circ} \mathrm{C}, 835^{\circ} \mathrm{C}$ dan 840 ${ }^{\circ} \mathrm{C}$ selama 20 jam. Hasil sintesis dikarakterisasi dengan XRD (X-Ray Diffraction) dan SEM (Scanning Electron Microscopy). Hasil analisis spektrum XRD yang telah diolah menggunakan celref, menunjukkan bahwa secara umum sampel-sampel yang dihasilkan sudah membentuk fase BPSCCO-2212 (ditunjukkan adanya puncakpuncak Bi-2212) dan sudah terorientasi (ditunjukkan adanya puncak-puncak dengan $h=k=0, l$ bilangan genap). Dari hasil perhitungan diperoleh nilai fraksi volume tertinggi pada suhu sintering $830{ }^{\circ} \mathrm{C}$ dengan nilai $F V=66,97 \%$ dan nilai derajat orientasi tertinggi pada suhu $825{ }^{\circ} \mathrm{C}$ dengan nilai $P=76,54 \%$. Hasil perekam foto SEM secara umum menunjukkan bahwa kristal yang terbentuk sudah terorientasi.
\end{abstract}

\section{Pendahuluan}

Superkonduktor merupakan suatu bahan dengan konduktivitas tak hingga, karena sifat resistivitas nol yang dimilikinya dan dapat melayang dalam medan magnet. Kedua sifat ini tampak pada saat bahan berada dibawah kondisi parameter kritisnya (Sukirman, 2010).

Sejak ditemukan oleh H.K Onnes, penelitian tentang bahan superkonduktor terus dilakukan dengan harapan mendapatkan bahan superkonduktor dengan sifat-sifat karakteristik yang lebih baik. Pada tahun 1988 ditemukan superkonduktor kuprat (CuO) berbasis $\mathrm{Bi}$, yaitu $\mathrm{Bi}-\mathrm{Sr}-\mathrm{Ca}-\mathrm{Cu}-\mathrm{O}$ dengan suhu kritis $100{ }^{\circ} \mathrm{K}$. Superkonduktor sistem Bi-Sr-Ca-Cu-O merupakan fase superkonduktor suhu tinggi (SKST) karena suhu kritisnya yang relatif tinggi (Darminto dan Rahmawati, 2009).

superkonduktor BSCCO memiliki 3 fase, yaitu fase $2201\left(10^{\circ} \mathrm{K}\right)$, fase $2212\left(80^{\circ} \mathrm{K}\right)$, dan fase 2223 $\left(110^{\circ} \mathrm{K}\right)$. BSCCO memiliki sifat mekanik yang bagus, sehingga mudah dibentuk, tidak mudah patah, tidak beracun dan dapat dikembangkan untuk pembuatan lapisan tipis (Purwati, 2002).

Sistem Bi-2212 mempunyai lapisan $\mathrm{CuO}_{2}$ ganda, dua lapisan semikonduktor $\mathrm{BiO}$ dan lapisan isolator SrO. Di dalam kristal, Bi dan Sr mempunyai valensi masing-masing +3 dan +2. Bi-2212 mempunyai 2 lapisan $\mathrm{CuO}_{2}$ (Darminto,2009). Kristal tunggal (susunan kisi-kisi atom yang teratur dan berulang) ini tidak bersifat konduktif jika $\delta$ (kandungan doping oksigen) $=0$, dan bersifat

\footnotetext{
* Corresponding author.

E-mail addres: (a)suprihatin.itb@yahoo.com, (b) yanti.yulianti@fmipa.unila.ac.id
} 
superkonduktif (dibawah Tc suhu ketika material menjadi superkonduktif) jika $\delta$ lebih besar dari 0 . Proses pemberian doping dapat dilakukan dengan menambah kandungan oksigen yang membentuk lapisan $\mathrm{BiO}$ dan $\mathrm{SrO}$ pada sistem $\mathrm{Bi}-\mathrm{Sr}-\mathrm{Ca}-\mathrm{Cu}-\mathrm{O}$. Penambahan ion-ion oksigen ini akan mempengaruhi keadaan-keadaan elektronelektron pada bidang kuprat sehingga mengakibatkan ketidakseimbangan elektronik (Rahmawati, 2009).

Diantara superkondiktor berbasis bismut, senyawa superkonduktor BPSCCO berfase $\mathrm{Bi}_{2} \mathrm{Sr}_{2} \mathrm{CaCu}_{2} \mathrm{O}_{8}{ }^{+}$(Bi-2212) banyak dijadikan model penelitian, seperti halnya penelitian yang dilakukan oleh (Sari, 2015) tentang pengaruh variasi suhu dalam sintesis superkonduktor Bi-2212 dengan doping $\mathrm{Pb}$ diperoleh nilai fraksi volum tertinggi pada suhu $830{ }^{\circ} \mathrm{C}(\mathrm{FV}=90,10 \%)$ dan nilai derajat orientasi terbaik diperoleh pada suhu $825^{\circ} \mathrm{C}(\mathrm{P}=59,31 \%)$.

Kendala yang dihadapi pada aplikasi bahan superkonduktor adalah sifat superkonduktifitas bahan akan muncul pada suhu yang amat rendah jauh dibawah $0{ }^{\circ} \mathrm{K}$. Hal ini mulai dapat teratasi setelah ditemukannya superkonduktor temperatur tinggi atau superkonduktor suhu tinggi (SKST), yang pada umumnya berupa senyawa multikomponen, memiliki multifase bersifat anisotropis yang berhubungan dengan struktur berlapis dan efek fluktuasi termal (Darminto dkk, 1999).

Ada beberapa metode dalam sintesis kristal superkonduktor Bi-2212, diantaranya adalah metode kopresipitasi dan metode pencampuran basah (Rahmawati, 2009). Dalam penelitian kali ini dilakukan dengan variasi suhu sintering dalam sintesis superkonduktor BPSCCO-2212 menggunakan metode pencampuran basah. Hasil yang diperoleh dikarakterisasi menggunakan X-Ray Diffraction (XRD) untuk mengetahui tingkat kemurnian fase yang terbentuk, dan Scanning Electron Microscopy (SEM) untuk mengetahui struktur mikro dari sampel. Kemudian data XRD diolah menggunakan Celref.

\section{Metode Penelitian}

Langkah pertama:Metode yang digunakan untuk menghasilkan sampel superkonduktor $\mathrm{Bi}_{1,8} \mathrm{~Pb}_{0,2} \mathrm{Sr}_{2} \mathrm{CaCu}_{2} \mathrm{O}$ ialah reaksi padatan (solid state reaction method) dengan pencampuran basah yaitu melaui pencampuran bahan $\mathrm{Bi}_{1,8} \mathrm{~Pb}_{0,2} \mathrm{Sr}_{2} \mathrm{CaCu}_{2} \mathrm{O}$ dengan $\mathrm{HNO}_{3}$ dan aquades, kemudian pemanasan pada suhu $70{ }^{\circ} \mathrm{C}$ selama 24 jam, pengeringan pada suhu $300{ }^{\circ} \mathrm{C}, 400{ }^{\circ} \mathrm{C}$ dan $600{ }^{\circ} \mathrm{C}$ selama $40 \mathrm{jam}$, penggerusan, presing, kalsinasi dengan suhu $800{ }^{\circ} \mathrm{C}$ selama 20 jam, penggerusan kembali, presing dan sintering dengan variasi suhu sintering $825^{\circ} \mathrm{C}, 830{ }^{\circ} \mathrm{C}, 835^{\circ} \mathrm{C}$ dan $840^{\circ} \mathrm{C}$.

Langkah kedua: Sampel yang telah diperoleh dikarakterisasi dengan menggunakan XRD dan $\mathrm{SEM}$, dan dari hasil XRD dianalisis menggunakan celref. Untuk mengetahui pertumbuhan fase BPSCCO-2212 yang terbentuk, sampel dikarakterisasi dengan pengukuran spektrum difraksi sinar-X (XRD). Spektrum XRD Superkonduktor BPSCCO Fase 2212 yang menjadi acuan standard dalam penelitian ini telah dihasilkan oleh Mannabe (1988) ditampilkan pada Gambar 1.

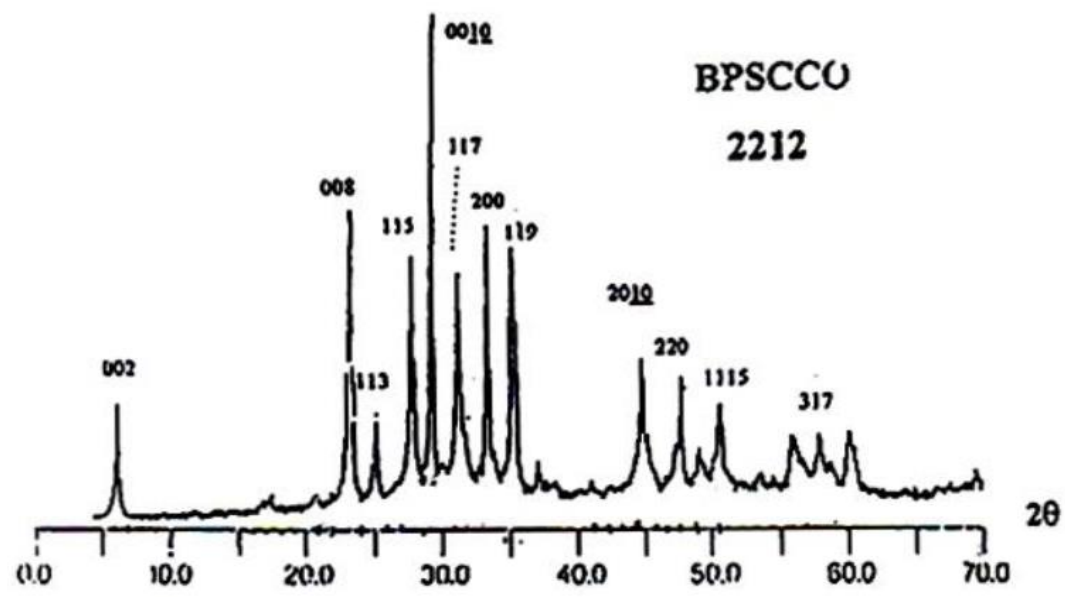

Gambar 1. Spektrum XRD Superkonduktor BPSCCO fase 2212.

Kemudian hasil pengukuran difraksi sinar-X dari masing-masing sampel dibandingkan dengan spektrum difraksi sinar-X yang dihasilkan oleh C.Mannabe pada Gambar 1 dengan bantuan program Celref. Hasil pola XRD yang telah dianalisi menggunakan Celref akan diberikan penomoran puncak dan nilai dari $h k l$ puncak tersebut, misalnya puncak 1(002) bearti bahwa nomor puncak 1 dengan $h=$ $0, k=0$, dan $l=2$. Selanjutnya untuk mengetahui tingkat kemurnian fase pada masing-masing sampel maka hasil yang telah diolah menggunakan Celref dihitung fraksi volum (FV), impuritas (I) dan derajat orientasi $(P)$ menggunakan Persamaan 1, 2 dan 3. 


$$
\begin{aligned}
F V & =\frac{\sum 1(2212)}{\text { Itotal }} \times 100 \% \\
P & =\frac{\sum 1(00 l)}{\sum 1(2212)} \times 100 \% \\
I & =100 \%-\mathrm{FV}
\end{aligned}
$$

dengan $F V$ adalah Fraksi volume fase BPSCCO-2212, $P$ adalah Derajat orientasi, $I$ adalah Impuritas, $I_{\text {total }}$ adalah Intensitas total, $I_{(2212)}$ adalah Intensitas fase 2212 , dan $I_{(0 o l)}$ adalah intensitas $\mathrm{h}=\mathrm{k}=0$ dan $l$ bilangan genap.

\section{Hasil dan Pembahasan}

\subsection{Analisis Spektrum XRD}

Dari hasil perhitungan diketahui bahwa untuk tiap variasi suhu sintering fraksi volum yang diperoleh juga berbeda. Secara umum penambahan suhu sintering yang dilakukan tidak selalu di ikuti dengan kenaikan nilai fraksi volum yang diperoleh. Spektrum difraksi yang diperoleh pada masing-masing sampel dengan veriasi suhu sintering dan lama kalsinasi selama 10 jam dengan suhu $800{ }^{\circ} \mathrm{C}$ menunjukkan intensitas puncak yang berbeda. Namun bukan bearti dengan penambahan suhu sintering yang dilakukan membuat intensitas puncak naik secara siknfikan. Hasil pengolahan hasil XRD pada bahan BPSCCO-2212 untuk tiap suhu sintering terlihat pada Gambar 2 sampai Gambar 5.

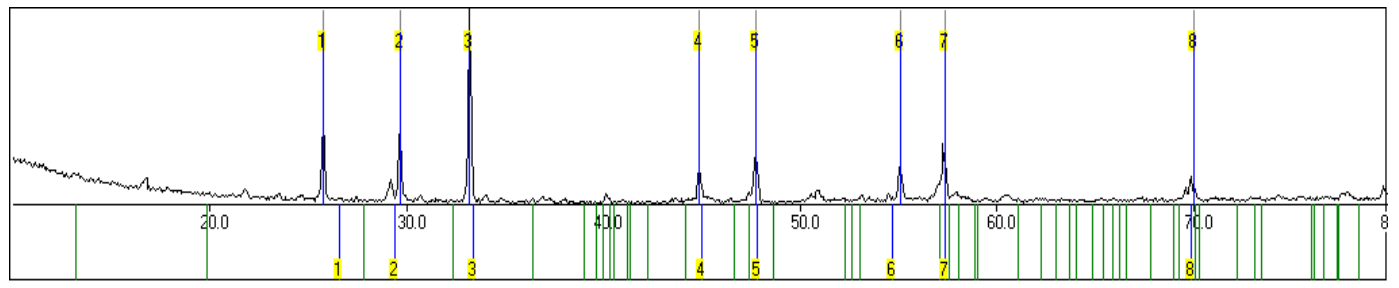

Gambar 2. Hasil analisis spektrum XRD pada sampel BPSCCO-2212/825 ${ }^{\circ} \mathrm{C}$.

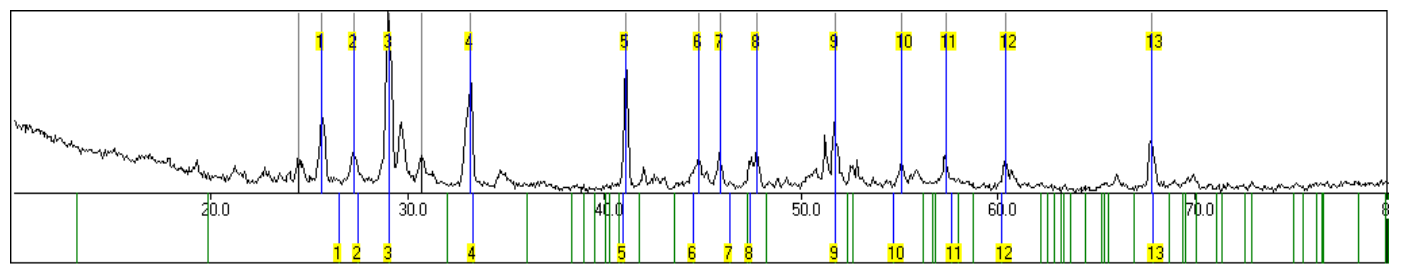

Gambar 3. Hasil analisis spektrum XRD pada sampel BPSCCO-2212/830 ${ }^{\circ} \mathrm{C}$.

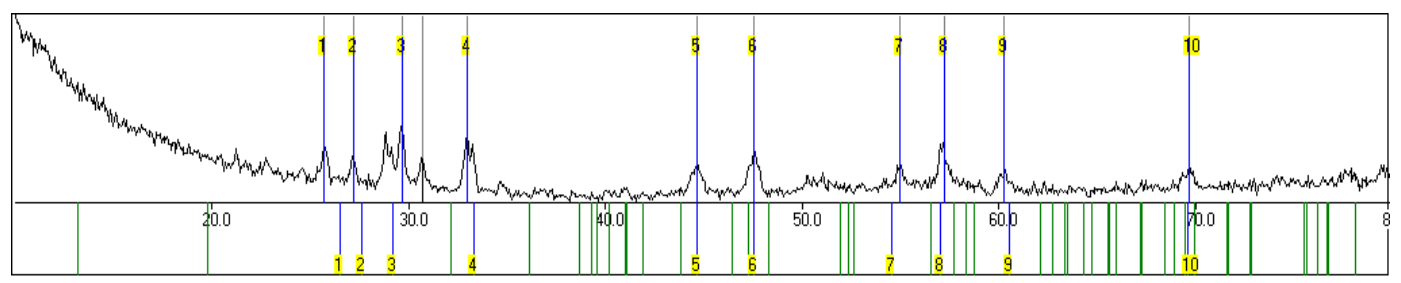

Gambar 4. Hasil analisis spektrum XRD pada sampel BPSCCO-2212/835 ${ }^{\circ} \mathrm{C}$. 


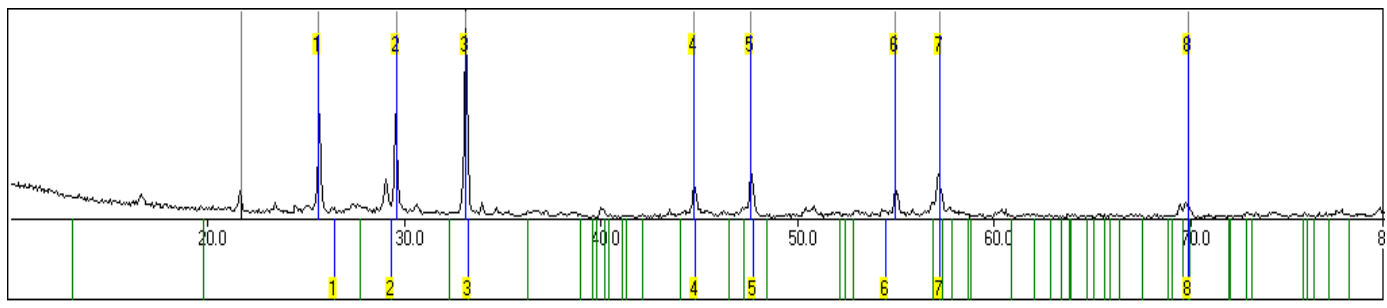

Gambar 5. Hasil analisis spektrum XRD pada sampel BPSCCO-2212/840 ${ }^{\circ} \mathrm{C}$.

Berdasarkan pengukuran spektrum difraksi sinar-X (XRD) (Gambar 2-5) hasil analisis masingmasing sampel yang telah diolah menggunakan Celref dihitung fraksi volum (FV), impuritas (I) dan derajat orientasi $(P)$ menggunakan persamaan 1, 2 dan 3. Puncak-puncak fase Bi-2212 dan puncak fase impuritas yang terbentuk pada masing-masing sampel akan berpengaruh terhadap fraksi volum, impuritas dan derajat orientasi yang di peroleh. Nilai fraksi volum, impuritas dan derajat orientasi dari masing-masing sampel dapat dilihat pada Tabel 1.

Tabel 1. Hasil perhitungan fase BPSCCO-2212

\begin{tabular}{ccccc}
\hline No & Suhu Sintering & $\begin{array}{c}\text { Fraksi Volum } \\
(F V \%)\end{array}$ & $\begin{array}{c}\text { Impuritas }(I \\
\%)\end{array}$ & $\begin{array}{c}\text { Derajat Orientasi }(P \\
\%)\end{array}$ \\
\hline 1 & $825^{\circ} \mathrm{C}$ & 64,84 & 35,16 & 76,54 \\
2 & $830^{\circ} \mathrm{C}$ & 66,97 & 33,03 & 33,36 \\
3 & $835^{\circ} \mathrm{C}$ & 38,10 & 61,90 & 63,49 \\
4 & $840^{\circ} \mathrm{C}$ & 64,28 & 35,72 & 73,73 \\
\hline
\end{tabular}

Fraksi volum terbesar yang diperoleh pada sampel BPSCCO-2212 adalah $66,97 \%$ dengan suhu sintering $830{ }^{\circ} \mathrm{C}$, namun nilai derajat orientasi yang diperoleh sangat kecil yaitu 33,36 \%. Sedangkan derajat orientasi terbesar diperoleh pada suhu $825{ }^{\circ} \mathrm{C}$ sebesar $76,54 \%$ dengan nilai fraksi volum sebesar $64,84 \%$. Dan nilai fraksi volum terkecil diperoleh pada suhu $835{ }^{\circ} \mathrm{C}$ yaitu $38,10 \%$, dengan nilai drajat orientasi $63,49 \%$. Secara umum keseluruhan fraksi volum dan derajat orientasi yang dihasilkan cukup baik walaupun kenaikan suhu sintering yang diberikan tidak selalu mempengaruhi kenaiakan nilai fraksi volum dan derajat orientasi yang diperoleh.

\subsection{Analisis SEM}

Karakteristik struktur mikro bahan superkonduktor BPSCCO-2212 dengan variasi suhu sintering $\left(825^{\circ} \mathrm{C}, 830^{\circ} \mathrm{C}, 835^{\circ} \mathrm{C}\right.$ dan $\left.840^{\circ} \mathrm{C}\right)$ dapat dilihat pada Gambar 6. Pengambilan gambar sampel yang dikarakterisasi menggunakan perbesaran 3000x.

Berdasarkan hasil perekam foto SEM (Gambar 6) secara keseluruhan menunjukan bahwa sampel dalam keadaan baik, yaitu dengan ditunjukkan bahwa keadaan struktr mikro yang terbentuk dalam berbentuk lempeng-lempeng yang tersusun searah dan ruang kosong antar lempeng terlihat lebih sedikit. relatif sedikit. Bentuk lempengan ini merupakan ciri struktur mikro dari BSCCO. 

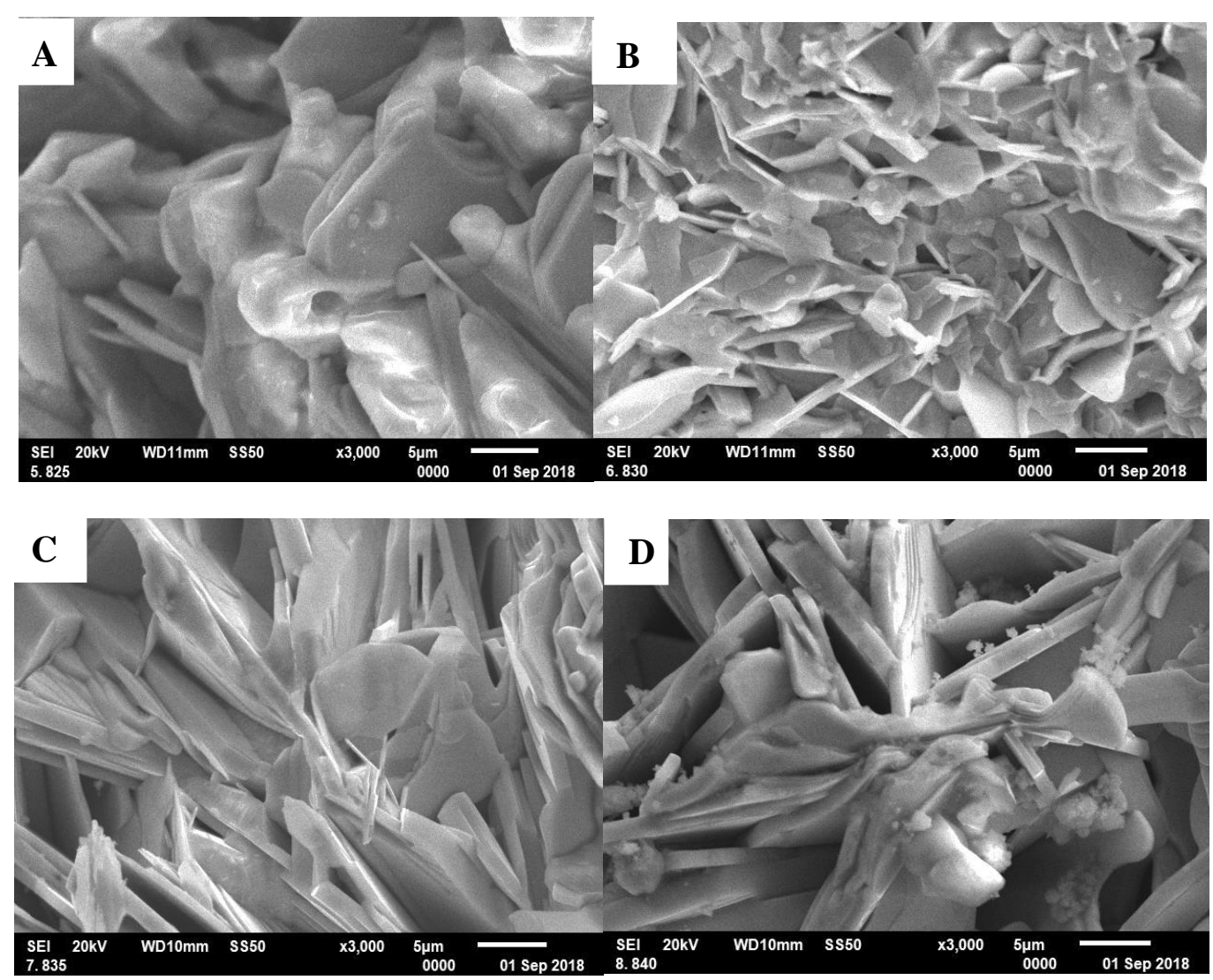

Gambar 6. Hasil rekam foto SEM pada sampel dengan variasi suhu sintering (A) BPSCCO$2212 / 825^{\circ} \mathrm{C}$, (B) $\left.\mathrm{BPSCC}\right)-2212 / 830^{\circ} \mathrm{C}$, (C) BPSCCO $-2212 / 835^{\circ} \mathrm{C}$ dan (D) BPSCCO$2212 / 840^{\circ} \mathrm{C}$ dengan perbesaran masing-masing 3000x.

\section{Kesimpulan}

Berdasarkan hasil penelitian, kesimpulan yang dapat diambil yaitu Penambahan suhu sintering tidak selalu mempengaruhi kenaikan nilai fraksi volum (FV) dan nilai derajat orientasi (P) yang diperoleh. Fraksi volum (FV) tertinggi diperoleh pada bahan superkonduktor BPSCCO-2212 dengan suhu sintering $830{ }^{\circ} \mathrm{C}(66,97 \%)$ dengan impuritas ( I ) terendah $(33,03 \%)$. Bahan superkonduktor BPSCCO-2212 dengan suhu $825{ }^{\circ} \mathrm{C}$ memiliki nilai derajat orientasi (P)tertinggi $(76,54 \%)$. Hasil perekam foto SEM pada masing-masing sampel dengan variasi suhu sintering $\left(825{ }^{\circ} \mathrm{C}-840{ }^{\circ} \mathrm{C}\right)$ menunjukkan bahwa kristal yang terbentuk sudah terorientasi.

\section{Daftar Pustaka}

Budianto, F. dan Darminto. 2011. Sintesis superkonduktor $\mathrm{NdBa}_{2} \mathrm{Cu}_{2} \mathrm{O}_{7-\delta}$ nanokristal dengan metode basah. Jurnal Seminar Nasional Pascasarjana XI. ITS. Surabaya. ISBN No. Hlm. 2-4.

Darminto dan Rahmawati, L. 2009. Nano kristalisasi superkonduktor $(\mathrm{Bi}, \mathrm{Pb})_{2} \mathrm{Sr}_{2} \mathrm{Ca} \mathrm{Cu} \mathrm{O}_{8+\delta}$ dengan metode pencampuran basah. Jurnal Dasar. Vol. 4 No.2. Hlm 75-80.

Darminto., Nugroho, A.A., Rusydi, A., Menovsky, A.A., dan Loeksmanto. 1999. Variasi tekanan oksigen dalam penumbuh kristal tunggal superkonduktor $\mathrm{Bi}_{2} \mathrm{Sr}_{2} \mathrm{CaCu}_{2} \mathrm{O}_{8-\delta}$ dan pengaruhnya. Prosiding ITB. Vol. 31. No. 3. Hlm.12-14.

Lydia Rohmawati dan Darminto. 2012. Nanokristalisasi superkonduktor (bi, $\mathrm{Pb})_{2} \mathrm{Sr}_{2} \mathrm{CaCuO}_{8+\delta}$ dengan metode pencampuran basah. Jurnal Berkala Fisika Indonesia. Vol. 4. No. 1 dan 2. Hlm. 22-26.

Sukirman, E. Y. Purwamargapratala, M. N. Indro, A. P. Purnomo. 2010. Sintesis Superkonduktor YBCO-123 dengan Metode Evaporasi. Prosiding Seminar Nasional Fisika 2010. Hlm. 184-193. 